\title{
Do resource declines increase predation rates on North Pacific harbor seals? A behavior-based plausibility model
}

\author{
Alejandro Frid ${ }^{1, *}$, Gregory G. Baker ${ }^{2}$, Lawrence M. Dill ${ }^{1}$ \\ ${ }^{1}$ Behavioural Ecology Research Group, Department of Biological Sciences, and ${ }^{2}$ School of Computing Science, \\ Simon Fraser University, 8888 University Drive, Burnaby, British Columbia V5A 1S6, Canada
}

\begin{abstract}
Harbor seals Phoca vitulina and other pinnipeds in the Gulf of Alaska have declined since the 1980s. The search for causation has considered top-down and bottom-up influences as independent factors. Research on other systems, however, has revealed that resource availability and predator densities synergistically determine the predation rates experienced by intermediate consumers. From this premise we developed a dynamic state variable model of behavior for the declining harbor seal population of Prince William Sound, Alaska. We modeled separate scenarios in which seals were prey to (1) transient killer whales Orcinus orca at and near the surface and Pacific sleeper sharks Somniosus pacificus throughout the water column, or (2) killer whales only. In both scenarios, resource decrements reduced the time spent by seals at the haulout (a refuge lacking food), increased the time spent at foraging areas, and lengthened surface intervals and dive durations. Because of this behavioral compensation, per capita fish consumption remained relatively constant, but predation rates increased as resources declined, despite fixed predator densities. Foraging effort and predation rates increased further when energy stores were lower at the onset of simulation periods, but in all scenarios seals not killed by predators had achieved a high level of energy stores by the reproductive season. These behavioral mechanisms proposed by the model potentially explain — at least partially — why the population has been declining while seals have maintained good energy stores throughout temporal shifts in resource availability. More generally, simulations suggest that overfishing and other factors that reduce fish populations indirectly increase predation rates on seals, but data are needed to test this hypothesis. Our model also encompasses a broader ecosystem perspective by predicting how resource level determines the relative strength of trait- and density-mediated interactions, whereby predators of seals indirectly affect fish populations by influencing the foraging behavior and density of seals. The behavioral modeling approach presented here is an additional tool for resource managers attempting to optimize fisheries exploitation and pinniped conservation.
\end{abstract}

KEY WORDS: Predation risk · Resource availability $\cdot$ Harbor seal $\cdot$ Phoca vitulina $\cdot$ Dynamic state variable model · Pinniped declines · Optimal diving · Prince William Sound · Indirect interactions

\section{INTRODUCTION}

Several pinniped populations of the eastern North Pacific have declined since the 1980s. The search for causation has considered top-down and bottom-up forces separately (e. g. Trumble \& Castellini 2002a, National Research Council 2003, Springer et al. 2003). Research on other systems, however, has revealed that resource availability and predator densities are inextricably linked in determining the predation rates experienced by intermediate consumers (e.g. Anholt \& Werner 1995, Krebs et al. 1995, Sinclair \& Arcese 1995, Biro et al. 2003). Thus, 'bottom-up versus top-down' questions are likely to over-simplify North Pacific pinniped declines. 
This assertion builds on the behavioral ecological framework in which individuals optimize trade-offs between predator avoidance and resource acquisition (Lima \& Dill 1990), and the optimal level of risk-taking (or conversely, of investment in antipredator behavior) depends on the individual's energetic state. Individuals in low energetic states must take greater risks to avoid either imminent starvation or loss of reproductive potential, and therefore incur higher predation rates than individuals in higher energetic states. Resource scarcity might reduce rates of energy gain and increase the frequency of poor energetic states in the population, indirectly increasing risk-taking and predation rates (e.g. McNamara \& Houston 1987, Anholt \& Werner 1995, Sinclair \& Arcese 1995, Biro et al. 2003, Luttbeg et al. 2003).

The behavioral ecological framework extends to the community level through trait-mediated indirect interactions (TMII). Top predators might indirectly affect the population dynamics of a resource species by influencing the habitat selection and foraging rates of an intermediate consumer. These indirect effects could interact with density-mediated indirect interactions (DMII): predators not only affect the distribution and per capita foraging rates of consumers (the first step of a TMII), but also their overall density through direct mortality (the first step of a DMII) (Luttbeg et al. 2003, Werner \& Peacor 2003).

These concepts have yet to be applied to the understanding of large-scale systems in the North Pacific. Consider our case study, harbor seals Phoca vitulina in Prince William Sound (PWS), Alaska. This population declined by $63 \%$ between 1984 and 1997 (Frost et al. 1999, Ver Hoef \& Frost 2003) and its numbers are still depressed (G. M. Blundell unpubl. data). Following a peak in 1988, the biomass of Pacific herring Clupea pallasi, a near-surface resource important to seals (Iverson et al. 1997), dropped $95 \%$ to a low point in 2001 (Thomas \& Thorne 2003) and its apparent recovery did not begin until 2003 (R.E. Thorne unpubl. data). The herring collapse stemmed from the combined effects of an oceanographic regime shift that began in the late 1970s and which affected the abundance of many fish species (Anderson \& Piatt 1999), the 1989 Exxon Valdez oil spill, and overfishing (Thomas \& Thorne 2003). Despite dramatic changes in resources, a conundrum surrounding the harbor seal decline is that individual seals studied in recent years have very good fat reserves (Fadely 1997, Trumble \& Castellini 2002b, K. J. Frost unpubl. data), and the pregnancy rates of adults ( $\geq 6$ yr old) appear high (100\% of 11 adult females sampled in PWS between 2000 and 2002 were pregnant; A. Hoover-Miller unpubl. data). A Leslie matrix projection model suggests that resource limitation may have initiated the decline in the mid 1980s - a period for which body condition data are unavailable to assess nutritional stress - but additional mortality was necessary to sustain the decline (R. J. Small unpubl. data). Thus, interactions between energy state, predation risk and resource levels require further examination. Transient killer whales Orcinus orca are well known predators of seals at and near the surface (Saulitis et al. 2000). Pacific sleeper sharks Somniosus pacificus, which use the entire water column (L. Hulbert et al. unpubl. data), are another potential predator.

Herein we present a dynamic state variable model (Clark \& Mangel 2000) that establishes the theoretical plausibility that declining resources elevate predation rates on seals even if predator density does not increase. Our computer experiments contrasted seal behavior, survival and reproduction between 3 resource levels: a baseline level, twice the baseline, and half the baseline. This was done factorially for 2 levels of energy reserves at the onset of simulation periods: high (90\% of maximum) and low (50\% of maximum). Because the predatory role of killer whales is well established while that of sleeper sharks is assumed (see 'Methods-Model system and structure'), we modeled separate scenarios in which seals were threatened by (1) killer whales and Pacific sleeper sharks, but with risk from sharks at a much lower level than risk from killer whales, or (2) killer whales only.

Based on the body of theory discussed earlier, we expected declining resources and lower levels of initial energy reserves to elevate predation rates on seals by demanding more time exposed to risk in foraging areas and less time in the safety of the haulout. Along with these broad-scale time allocation decisions, which have counterparts in myriad other systems (Lima \& Dill 1990), we needed to consider details of diving behavior. For seals and other aquatic foragers that breathe air (Boyd 1997), the time spent uploading oxygen at the surface is mutually exclusive with prey-searching, while also influencing foraging depth and time (Kramer 1988). The optimal organization of a dive cycle is predicted to respond to ecological factors such as prey distribution (e.g. Thompson \& Fedak 2001) and predation risk (Heithaus \& Frid 2003). Not surprisingly, a recent empirical analysis demonstrated that the functional response of pinnipeds to prey density is best understood by applying optimal diving theory (Mori \& Boyd 2004). Thus, we expected the greater risk-taking associated with resource scarcity to manifest at the scale of the dive cycle via longer surface intervals and dives (Heithaus \& Frid 2003). Although a large theoretical literature predicts optimal dive cycles under many conditions (e.g. Kramer 1988, Mori 1998, Thompson \& Fedak 
2001, Heithaus \& Frid 2003, Houston et al. 2003), it does not consider predation risk at multiple depth strata, as we do here. Further, our study is the first dynamic state variable model to explore how dive cycle organization contributes to survival and reproduction over multi-month periods.

Indirect interactions between top predators and resource species, as mediated by intermediate consumers such as seals, are inherent to marine communities (Dill et al. 2003). Single-species management is unlikely to solve marine conservation problems (Pauly et al. 2002, Alonzo et al. 2003). Thus, we placed our model in a broader ecosystem perspective by simulating the extent to which top predators influence fish populations by affecting the behavior and density of seals under different resource levels. We expected TMIIs to weaken and DMIIs to strengthen when energetic state and resource level were low, because antipredator behavior is less affordable then than when energetic state and resource levels are higher (Luttbeg et al. 2003).

\section{METHODS}

\section{Model system and structure}

This section describes the model and its assumptions. Appendix 1 (available at: www.int-res.com/ articles/suppl/m312p265_app.pdf) details model derivation and Appendix 2 (available at www.int-res.com/ articles/suppl/m312p265_app.pdf) and Tables 1 \& 2 describe parameterization.

Transient killer whales are the primary predator of seals at and near the surface, an assumption well supported by direct observations (Saulitis et al. 2000). We assume Pacific sleeper sharks to be predators at depth, but predation events involving them are unobservable from the surface and there is a dearth of data on pinniped-sleeper shark interactions. Stomach contents analyzed to date for sleeper sharks in the Gulf of Alaska do not provide compelling evidence of predation on seals. Only 1 of 36 samples of non-empty stomachs for sharks with pre-caudal lengths $\geq 2 \mathrm{~m}$ (the minimum size

Table 1. Phoca vitulina. Activity-specific energy and oxygen costs per $20 \mathrm{~s}$ time unit. See Appendix 1 (available at: www.int-res.com/articles/suppl/m312p265_app.pdf) for notation regarding location and decisions. Energetic costs were calculated from oxygen consumption during surface travel at $1 \mathrm{~m} \mathrm{~s}^{-1}$ and during resting at surface by a $63 \mathrm{~kg}$ harbor seal (Davis et al. 1985) using standard conversion factors. However, data were unavailable for travel between the surface and a depth stratum, and for resource search within a depth stratum, and these activities were assumed to be 65 and $75 \%$ as costly as surface swimming (see Williams et al. 2000), respectively. Similarly, energetic cost of remaining at refuge was assumed to equal that of resting at surface

\begin{tabular}{|lcccc|}
\hline Activity & $\begin{array}{c}\text { Location } \\
H(t)=h\end{array}$ & $\begin{array}{c}\text { Decision } \\
D(x, y, h, t)=d\end{array}$ & $\begin{array}{c}\text { Energetic cost (kJ) } \\
\alpha_{h, d}\end{array}$ & $\begin{array}{c}\text { Oxygen cost (ml) } \\
u_{h, d}\end{array}$ \\
\hline Remain at refuge or surface & $0,25,150$ & $d=h$ & 1.94 & - \\
Travel between habitats & $0,25,150$ & $\begin{array}{c}d \neq h \text { and } \\
d \neq 1,2,5\end{array}$ & 3.25 & 105.11 \\
Travel between surface and depth & $25,150,1,2,5$ & $d \neq h$ and \\
& $1>0$ & 2.11 & \\
Resource search at depth & $1,2,5$ & $d=h$ & 2.44 \\
\hline
\end{tabular}

Table 2. Phoca vitulina. Baseline parameter values $\left(10^{-6}\right)$ for probabilities of encountering and capturing a resource $\left(\lambda_{h}\right)$ or of being killed by predators per $20 \mathrm{~s}$ time unit when decision $D(x, y, h, t)=h$. Locations and decisions defined in Appendix 1 and Fig. 1. If $D(x, y, h, t) \neq h$, then (1) risk while traveling between surface habitats is $50 \%$ of that when remaining at more dangerous endpoint (e.g. $\left.\mu_{\text {shark }}[0,150]=0.5 \mu_{\text {shark }}[150,150]\right)$, and (2) risk while traveling between the surface and a depth stratum is $25 \%$ of that while searching for resources at that depth $\left(\right.$ e.g. $\left.\left.\mu_{\text {shark }}[5,150]\right)=0.25 \mu_{\text {shark }}[5,5]=\mu_{\text {shark }}[150,5]\right)$. Gross energy gains for Pacific herring and walleye pollock are 604.4 and $1531 \mathrm{~kJ}_{\text {fish }}^{-1}$, respectively. $\mu_{\text {shark }}(h, d), \mu_{\text {orca }}(h, d)$ : sleeper shark and killer whale predation probabilities, respectively

\begin{tabular}{|c|c|c|c|c|c|c|c|c|}
\hline \multirow{2}{*}{$\begin{array}{l}\text { Location } \\
H(t)\end{array}$} & \multicolumn{2}{|c|}{$\lambda_{h}$ for Pacific herring } & \multicolumn{2}{|c|}{$\lambda_{h}$ for walleye pollock } & \multicolumn{2}{|c|}{$\mu_{\text {shark }}(h, d)$} & \multicolumn{2}{|c|}{$\mu_{\text {orca }}(h, d)$} \\
\hline & Day & Night & Day & Night & Day & Night & Day & Night \\
\hline 0 & 0 & 0 & 0 & 0 & 0 & 0 & 0 & 0 \\
\hline 25 & 0 & 0 & 0 & 0 & 0.0182 & 0.169 & 10 & 6.60 \\
\hline 2 & 7.48 & 3330 & & & 0.127 & 0.271 & 1.30 & 3.30 \\
\hline 150 & 0 & 0 & 0 & 0 & 0.0182 & 0.169 & 5.00 & 0.858 \\
\hline 1 & 365 & 71.4 & 0 & 0 & 0.0357 & 0.155 & 2.00 & 1.32 \\
\hline 5 & 0 & 0 & 1650 & 17300 & 1.16 & 1.14 & 0 & 0 \\
\hline
\end{tabular}


we assume capable of killing adult seals) contained seal tissues (data for 2001 to 2002, Sigler et al. in press). Building an empirical understanding of seal-shark interactions will be a slow and expensive process, and it is the role of models to provide guidance on how to approach potentially relevant processes that have yet to be measured (Clark \& Mangel 2000). Thus, it is appropriate to consider danger from sleeper sharks in the model, particularly because in a sample of 429 PWS sharks, $25 \%$ had precaudal lengths of 2.0 to $2.8 \mathrm{~m}$ (B. Bechtol unpubl. data). Weight estimates for those lengths are approximately 100 to $200 \mathrm{~kg}$ (Sigler et al. in press), or 1.3 to 2.5 times the weight of the average adult seal (80 kg; K. J. Frost 1997, available at: www.evostc.state.ak.us/habitat/downloadables/ RN_seals.pdf). Consistent with the notion that the larger size classes of sharks might kill seals opportunistically, time-at-depth data indicate spatial overlap between seals and sharks (Frost et al. 2001, Frid et al. unpubl. data, L. Hulbert et al. unpubl. data).

Pacific herring Clupea pallas; and walleye pollock Theragra chalcogramma are the main resources sought by seals. Pollock are found deeper (Appendix 2) and contain about half the energy density of herring (Anthony et al. 2000), but can also be much larger. Based on prior surveys in the area (see Appendix 2), we assumed wet weights of $115 \mathrm{~g}$ for herring and $525 \mathrm{~g}$ for pollock for model parameterization. Ongoing studies with juvenile Steller sea lions Eumetopias jubatus suggest that adult harbor seals probably handle underwater the larger prey sizes of pollock assumed by the model (D. Tollit pers. comm.). Seals readily digest the extra biomass (Trumble et al. 2003), so the net energetic value per fish (independent of travel and search costs) is greater for pollock than for herring (Table 2, Appendix 2). Therefore, the model system has a vertical spatial structure in which choice of depth involves trade-offs between multiple predators and resource types, as well as oxygen-constrained travel and search times. Temporal trade-offs are created by day and night cycles; at night, fish biomass can increase in shallower strata while killer whale hunting activity appears reduced (R. W. Baird unpubl. data). This relative safety, however, is partly offset by nocturnal use of shallow depths by sharks (Appendix 2).

The model is specific to adult female seals with the potential for 20 subsequent reproductive years. Here, seals optimize trade-offs for conditions encountered during late winter and spring (Appendix 2), the $120 \mathrm{~d}$ leading to reproduction in early June. In the model, decisions are made every $20 \mathrm{~s}$ time unit. We used this small time step because, for many diving vertebrates, small differences in the duration of surface intervals between dives might have strong non-linear effects on energy gain and predation risk (Heithaus \& Frid 2003).

The model uses 2 internal states, energy reserves and oxygen stores. An environmental state variable abstracts potential habitats and depths (Fig. 1), as suggested by preliminary data on seal locations and fish distributions (Appendix 2). These locations are a haulout or refuge from predation without food, a nearshore habitat $500 \mathrm{~m}$ from the haulout that includes a surface location for oxygen uploading and a 40 m-deep foraging patch, and an offshore habitat $3 \mathrm{~km}$ from the haulout that includes a surface location and foraging patches at depths of 20 and $100 \mathrm{~m}$ (Fig. 1).

The seal's choice of habitat and depth is unconstrained by time of day or night, an assumption supported by empirical data (Frost et al. 2001). We also assume that depth choice occurs at the onset of a dive, rather than being based upon prey encounters during descent or ascent (Simpkins et al. 2001, Wilson 2003).

Model tractability required the following simplifications. Travel speed between surface habitats and depths is fixed at $1 \mathrm{~m} \mathrm{~s}^{-1}$. Although resource species in

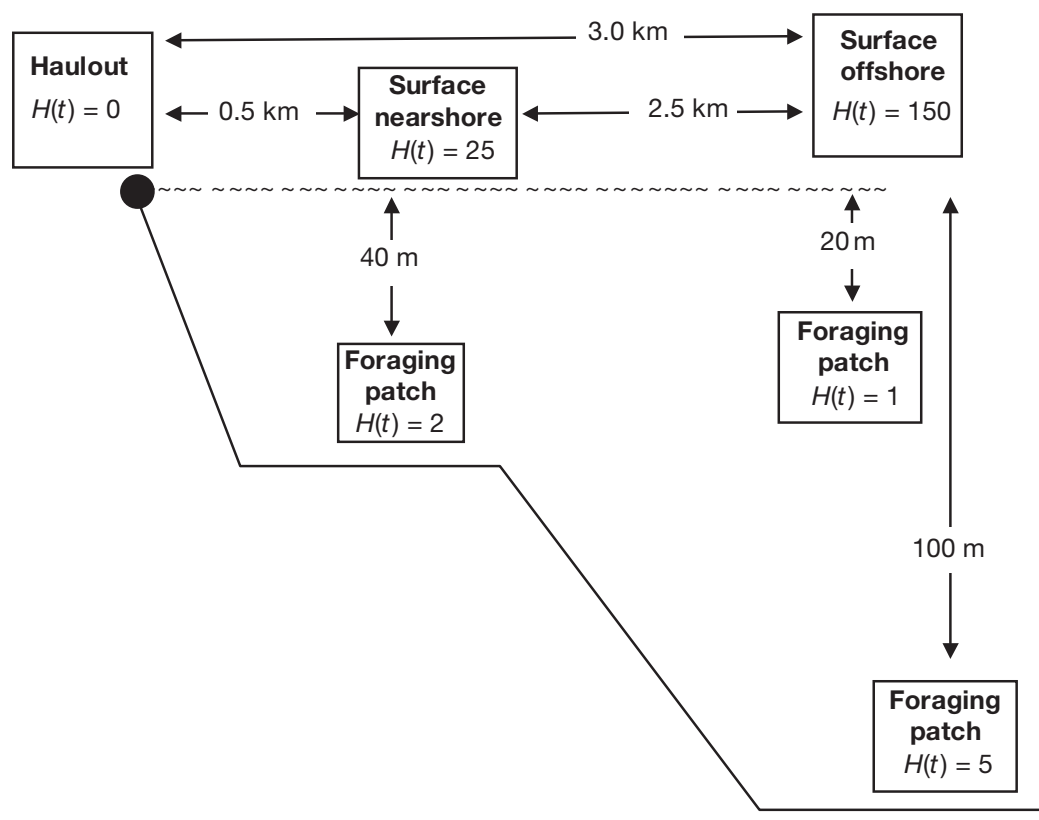

Fig. 1. Phoca vitulina. Spatial structure of model. Locations are represented by boxes that contain descriptive names and mathematical designation (see Appendix 1) in which values of $H(t)$ correspond to number of $20 \mathrm{~s}$ time units required to travel to given location from either the haulout (if switching surface habitats) or from the surface (if diving). Arrows: allowable decisions at each location; numbers with arrows: travel distance inherent to decisions; solid line: sea floor. See 'Methods' for details 
the wild might be schooling fishes, the expected rate of resource acquisition is parameterized as an average rate of encounter with and capture of individual fish. There is no resource depletion, nor intra- or interspecific competition, and predator and resource species have fixed behaviors. Buoyancy upthrust due to fat stores and depth (e.g. Beck et al. 2000) and anaerobiosis (Ydenberg \& Clark 1989) can affect optimal time allocation during diving, but these processes are not modeled.

\section{Computer experiments}

Solutions to the dynamic programming equations provided values for an optimal decision matrix for all combinations of state variables and time periods. Based on this matrix, we used forward iterations (Clark \& Mangel 2000) to predict behavior and fitness. Initial energy state was treated as an experimental variable with 2 levels, low and high initial energy states, representing 50 and $90 \%$ of the maximum value, respectively. These are the states at the start of forward iterations that send individuals onto different trajectories (Appendix 1). Resource level was a second experimental variable. High, medium and low resource levels were indexed, respectively, as 200, 100, and 50\% of baseline values for the location-specific probabilities of encountering and capturing a fish each $20 \mathrm{~s}$ time unit (Table 2, Appendix 2). Location-specific probabilities of encountering a predator per $20 \mathrm{~s}$ time unit remained unchanged (Table 2). This is equivalent to maintaining a fixed predator density because in the model predator behavior is invariable and seal behavior does not change within a time period.

Treatment combinations were simulated 1000 times each and we interpreted the results as predicted responses by populations with initial sizes of 1000 individuals under the simplifying assumption of no density-dependence (Clark \& Mangel 2000). Following Luttbeg et al. (2003), we quantify the relative size of trait- and density-mediated indirect effects of top predators on fish as proportional reductions of the number of fish eaten by seals due to risk avoidance versus density reduction, respectively (Appendix 1).

\section{RESULTS}

During all simulations, foraging occurred almost exclusively at night and at the $100 \mathrm{~m}$ foraging patch, where pollock were the only prey available. Refuge use was primarily diurnal. We first present results for the scenario in which both sharks and killer whales are assumed to be dangerous (Figs. 2 to 4), and follow with the main results from the scenario in which killer whales are assumed to be the only predator (Fig. 5).

The number of foraging trips (departures from the refuge) and dives made over the $120 \mathrm{~d}$ simulation period (Fig. 2A,B) and the average duration of each dive increased as resources became more scarce. Because travel time to the $100 \mathrm{~m}$-deep foraging patch is fixed at $200 \mathrm{~s}$ (100 s spent for descent or ascent), increases in dive duration imply that more time per dive was spent at the foraging patch (Fig. 2C). Although longer periods of oxygen loading at the surface were needed to support the longer dives (Fig. 2D), the proportion of the dive cycle spent at the foraging patch increased slightly with declining resources (Fig. 2E). These correlated sets of responses combined into an overall response whereby decrements in resource levels led to an increase and decrease, respectively, in the overall proportions of time at the $100 \mathrm{~m}$ foraging patch and at the refuge (Fig. 2F,G). Because of this behavioral compensation, the total number of fish eaten was similar across resource levels (Fig. 2H). At a given resource level, foraging effort and per capita fish consumption generally were greater and time at the refuge was smaller for the low than for the high initial energy state. However, at high resource levels the effect of energy state was smallest, and even absent in the case of dive cycle organization (Fig. 2).

Despite fixed predator densities, predation rates increased with declining resources and, at a given resource level, were higher when initial energy state was low (Fig. 3A). Nearly all survivors, however, were near the maximum energy state at the end of the simulation, regardless of initial state and resource level, except when resource level was lowest (Fig. 3B).

For both initial energy states, TMIIs strongly dominated and DMIIs were weak at high resource levels, whereas DMIIs dominated and TMIIs were very weak at mid- and low resource levels (Fig. 4). At high resource levels, TMIIs were stronger for the high than for the low initial energy state (the net reduction in fish eaten was $\sim 4 \%$ greater; Fig. 4 ).

When killer whales were assumed to be the only predator, behavioral responses to resource decrements were undistinguishable from the scenario with both predator types. Within a resource level, there were no differences in foraging effort and success (Fig. 5A-C), and therefore on TMIIs. These results indicate that killer whale risk alone determined diving behavior and other time allocation in simulations where both sharks and killer whales were assumed to be dangerous. However, due solely to predator-density effects, mortality rates within a resource level were higher in the scenario that included both predator types. Mortality rates at mid- and low resource levels in the killerwhale scenario, however, are approximately equal to 

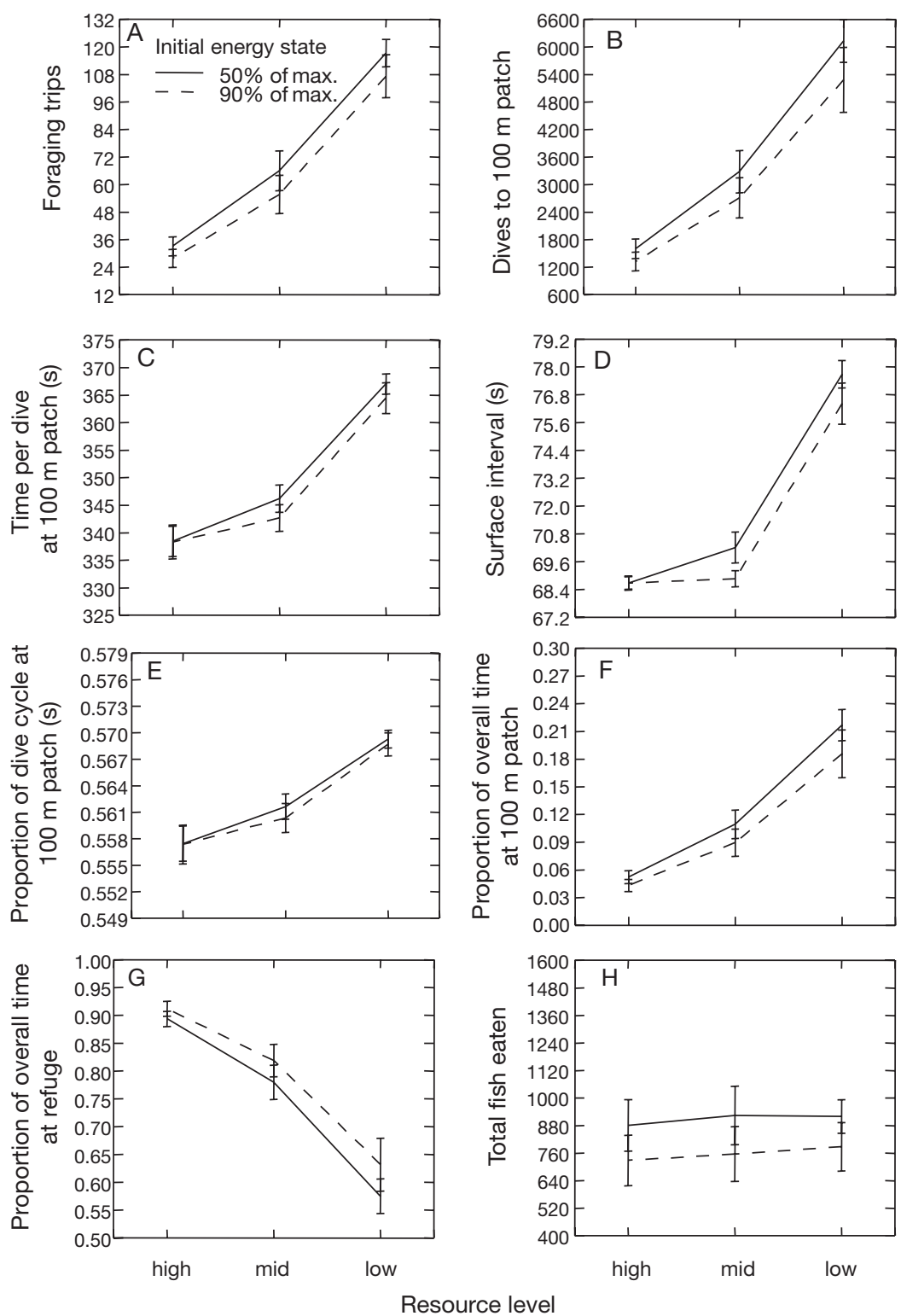

Fig. 2. Phoca vitulina. Effect of resource level and initial energy state on behavioral responses by individual seals during 120 d period simulated by forward iterations when sleeper sharks Somniosus pacificus and killer whales Orcinus orca are dangerous. Data are mean $( \pm \mathrm{SD})$ for individuals that avoided predation and starvation, surviving to terminal horizon $(\mathrm{N}=1000$ replicates per treatment, but only simulations in which seals survived to the terminal horizon are shown). Low and high initial energy-state treatments correspond to 50 and $90 \%$ of maximum energy state at start of simulation. High, medium (mid) and low resource levels were indexed, respectively, as 200,100, and $50 \%$ of baseline values for location-specific probabilities of encountering and capturing a fish (see Table 2 \& Appendix 2)

mortality rates at high and mid-resource levels, respectively, in the scenario that included both predator types (Fig. 5D). Thus, doubling resource level in the latter scenario decreased mortality rates to a similar degree as removing shark risk.

\section{DISCUSSION}

Our model formally establishes the theoretical plausibility that declining resources and lower energy states increase predation rates on harbor seals when predator density is assumed to remain constant. Our results are consistent with the principle that fewer resources and poor energy reserves demand a greater level of foraging effort that is attainable only by relaxing antipredator behavior (McNamara \& Houston 1987, Anholt \& Werner 1995, Sinclair \& Arcese 1995, Biro et al. 2003, Luttbeg et al. 2003).

Simulations indicate that synergistic effects of resources and predators might contribute to harbor seal declines via behavioral decisions occurring at 2 scales. At the scale of broad habitat selection, resource scarcity and lower energy state reduced the amount of time spent in the safety of the haulout and increased the time spent at risk in foraging areas. At the scale of dive cycle organization, declining resources and lower energy state led to longer surface intervals and dives. These responses increased the resource gain per dive and the proportion of the dive cycle spent at the foraging patch. The cost was more time spent where encounters with killer whales (the surface) and sleeper sharks (the $100 \mathrm{~m}$ patch) were most likely. Existing theory predicts that trade-offs between increased risk at the surface and energy gain are optimized by shortening surface intervals, despite the resulting decrease in proportion of the dive cycle at the foraging patch (unless a shallower patch is selected) and the lower rates of energy gain (Heithaus \& Frid 2003). Our simulations indicate, however, that the foraging costs of safer and shorter surface intervals become less affordable as resources decline or when initial energy state is lower.

The most relevant theoretical insight for the population decline of PWS seals is 2-fold. First, under model assumptions, individual seals can maintain a constant rate of foraging success through periods of resource scarcity if they invoke compensatory foraging effort, 

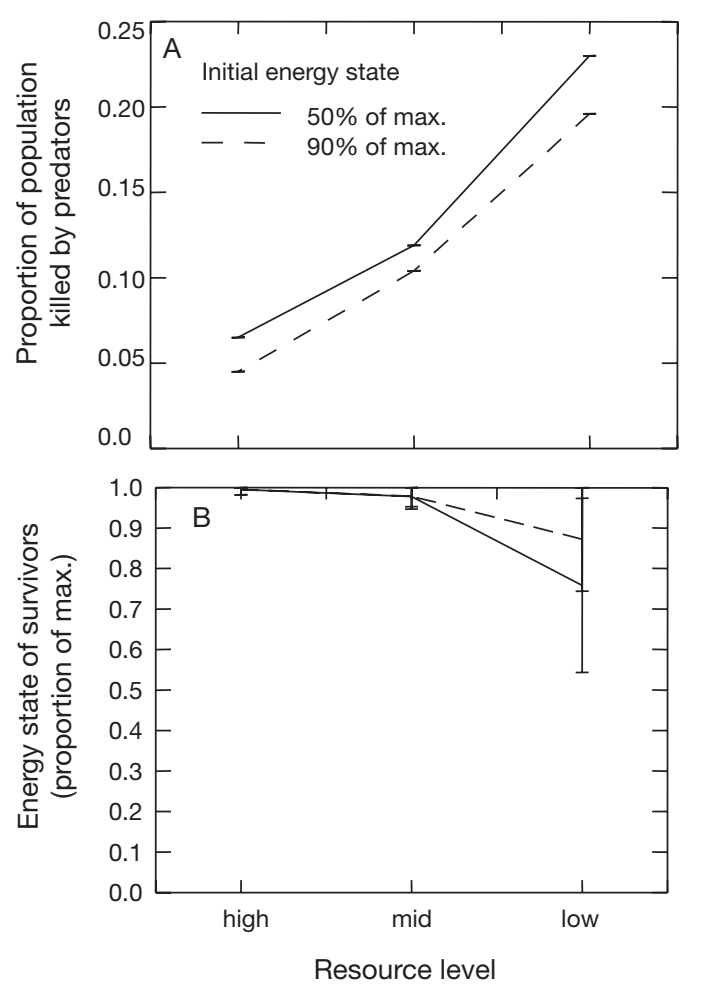

Fig. 3. Phoca vitulina. (A) Proportion of population killed by predators and (B) energy state of survivors (mean \pm SD) in relation to resource level and initial energy state when sleeper sharks Somniosus pacificus and killer whales Orcinus orca are dangerous. In addition to mortalities shown in (A), 15 individuals of low initial energy state starved when at low resource level. Further details are in Fig. 2 legend

but only at the cost of increased predation rates. Second, foraging effort and predation rates increase further if energy stores are lower at the onset of simulation periods, but in all scenarios seals not killed by predators achieve a high level of energy stores by the reproductive season. These behavioral mechanisms proposed by our application of the state-dependent optimal foraging paradigm potentially explain-at least partially - why the seal population has been declining while individuals have maintained good energy stores (Fadely 1997, Trumble \& Castellini 2002b, Trumble et al. 2003, K.J. Frost unpubl. data, A. Hoover-Miller unpubl. data) throughout temporal shifts in resource availability (Anderson \& Piatt 1999, Thomas \& Thorne 2003).

Our general conclusions are robust even if sleeper sharks are assumed not to be dangerous to seals. In our model, killer-whale predation increases with declining resources largely because resource decrements demand more dives, as well as longer periods at the surface for meeting the oxygen requirements of longer dive durations. Thus, cumulative surface time increases (Fig. 5C) raising encounter rates with killer whales.
A Initial energy state $50 \%$ of max.

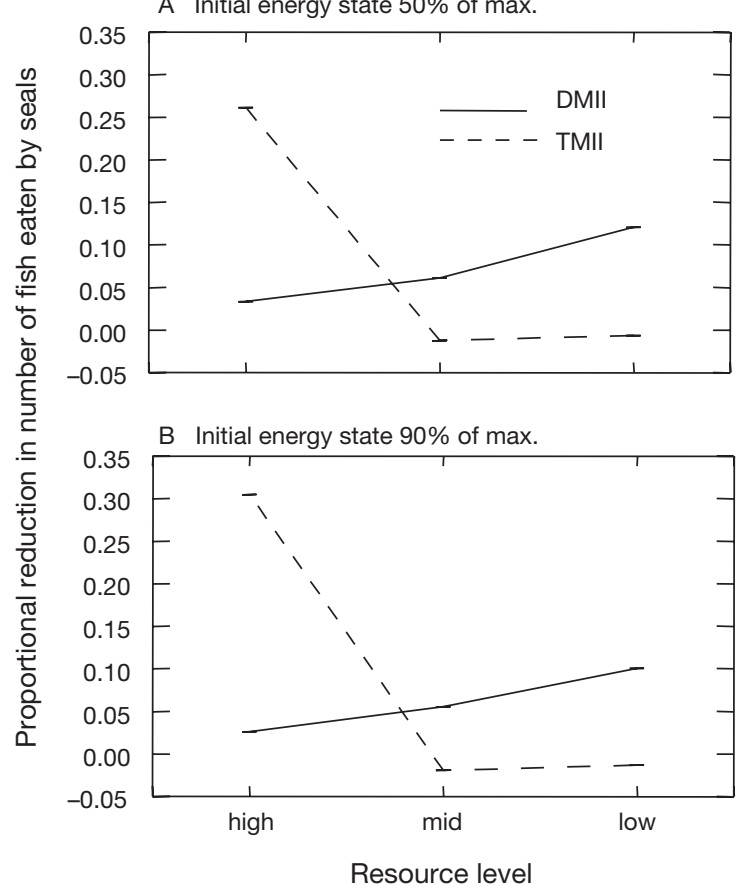

Fig. 4. Phoca vitulina. Relative strength of trait-mediated indirect interactions (TMII) and density-mediated indirect interactions (DMII) in relation to resource level when sleeper sharks Somniosus pacificus and killer whales Orcinus orca are dangerous. Note that TMIIs were slightly negative at midto low resource levels. This occurred because in the predatorfree reference case (see Appendix 1) seals rested at surface of the foraging area and did not use the refuge between foraging bouts. Thus, overall energy consumption and prey capture requirements were lower than in simulations with predation risk, which required that seals travel to refuge for safety between foraging bouts

In addition, more foraging effort correlates with less time in the safety of the haulout.

Our model also expands the concept of resourceand state-dependent TMIIs to intermediate consumers whose internal state depends not only on energy, but also on the level of oxygen available to seek resources. It reinforces the theoretical prediction that TMIIs strengthen and DMIIs weaken when resource level and energy state are high (Luttbeg et al. 2003). Thus, our model can inform conservation approaches not only for pinnipeds but also for broader ecosystem issues. For instance, resource managers strive to estimate the extent to which fisheries compete with pinnipeds, and the latter's effect on fish populations. Considering the distribution of energy states in the pinniped population and the indirect effects of top predators might improve these estimates. Our model's output could effectively become the input for existing ecosystem models where all participants are behaviorally inert (e.g. Okey \& Wright 2004). Whether 

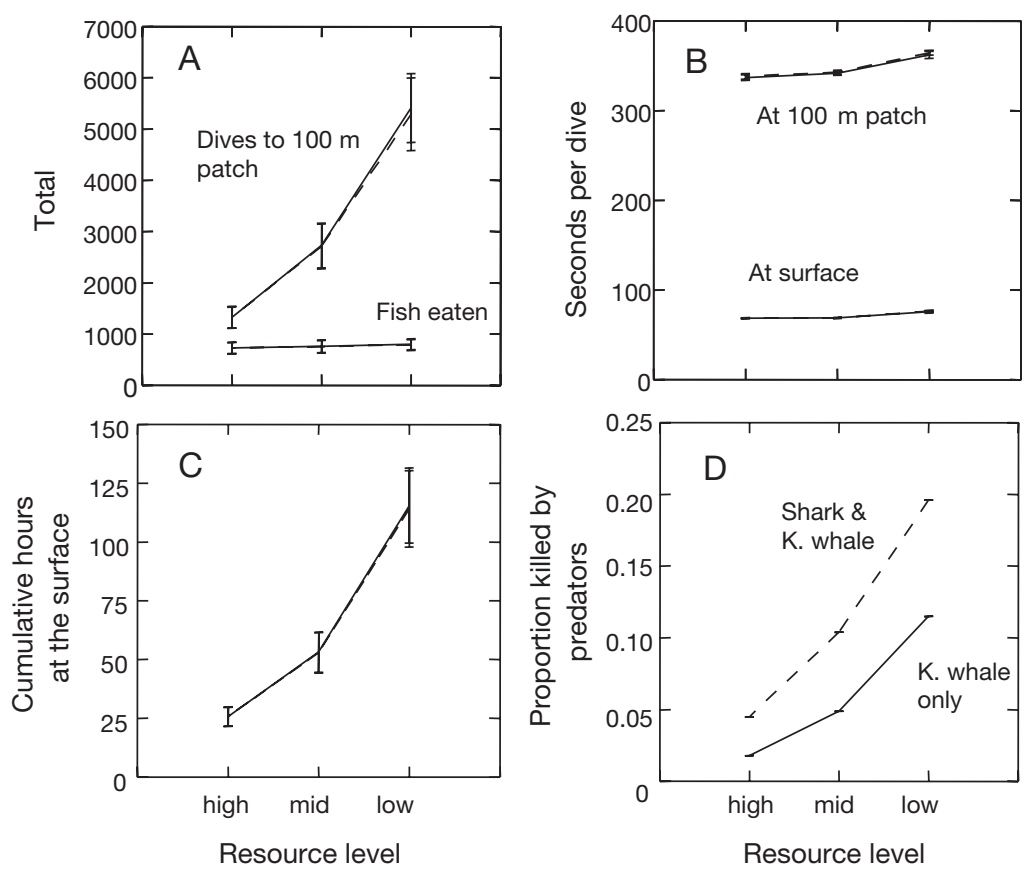

Fig. 5. Phoca vitulina. Sample output comparing responses to resource declines between simulations in which both predator types are assumed to be dangerous (dashed line) and simulations in which only killer whales Orcinus orca are assumed to prey on seals (continous line). Results are shown only for simulations in which initial energy state was high (results were similar when initial energy state was low). Because behavior did not respond to removal of shark risk, lines overlap for both predator scenarios in (A-C). (D) illustrates increases in predation rates during resource declines, with differences between predator treatments reflecting predator-density effects. Data A-C are means $( \pm S D)$. Further details as in legend to Fig. 2

dissecting responses to resources and risk into components of the dive cycle is relevant to understanding TMIIs or DMIIs could depend on the extent to which predators use the surface rather than deeper strata.

Our simulation results are consistent with some empirical studies. For example, at Sable Island, Nova Scotia, there is dietary overlap between sympatric harbor seals and grey seals Halichoerus gryphus. The harbor seal population has declined since the early 1990s, while grey seals have been increasing exponentially (Bowen et al. 2003 and references within). As suggested by Bowen et al. (2003), interspecific competition may have functionally reduced resource availability for harbor seals. During their population decline, harbor seals have experienced elevated rates of shark predation (Lucas \& Stobo 2000, Bowen et al. 2003), while maternal post partum mass and most other resourcesensitive life-history parameters have remained constant (Bowen et al. 2003). These data are consistent with our prediction that seals can cope with declining resources via compensatory foraging effort (Fig. 2), thus maintaining high energy reserves but at the cost of increased encounters with predators (Fig. 3). If real, greater risk-taking by Sable Island harbor seals may have resulted from behavioral mechanisms similar to those elucidated by simulations (see Fig. 2), but long-term trends in foraging behavior have yet to be analyzed in the context of competitioninduced resource declines. Consistent with our state-dependent risk-taking predictions (see Fig. 2), however, dive effort (measured as vertical meters traveled per hour) was inversely related to maternal post-partum mass during mid- and late- lactation (Bowen et al. 2001). Thus, it could well be that shark predation is the proximate cause of the Sable Island harbor seal decline, but resource scarcity leading to greater risk-taking is the ultimate cause.

Unfortunately, our predictions cannot be assessed by published studies on the behavior of Alaskan harbor seals during 1992 to 1997 (Frost et al. 2001, Lowry et al. 2001, Hastings et al. 2004), as these lack the requisite data on individual energy states and on resource and predator distributions. However, unpublished data on the behavior of harbour seal pups in PWS during 1997 to 1999 are consistent with the general results of our simulations. Pups were heavier and spent more time hauled and less time at sea during a year of abundant resources (1997) than during other years (K. J. Frost unpublished data). Also, decreases in foraging effort in response to more abundant resources are welldocumented for other pinnipeds (e.g. Arctocephalus gazelle, Mori \& Boyd 2004).

Is our model relevant to the recent and notorious population decline of the western stock of the Steller sea lion in Alaska (National Research Council 2003)? Hypotheses on the underlying causes of the sea lion decline have followed a dichotomous 'bottom-up versus top-down forcing' approach, with the apparent weight of the evidence leaning towards 'top-down forcing' (e.g. National Research Council 2003). Observed rises in predation rate and good body condition of adult females and pups, currently interpreted as indicating top-down forcing (Table 6.2 of National Research Council 2003), suggest that interactions between resource level and predation rate, as elucidated by our model, should be considered among the alternative hypotheses. Admittedly, foraging effort by adult females during summer has decreased during 
the period of population decline (Table 6.2 of National Research Council 2003), which does not support our predictions, but a broader seasonal scope is needed for assessing the behavioral mechanisms influencing mortality rate.

The significance of our behavioral modeling approach is that it provides a rigorous way of considering pinniped declines that transcends the 'top-down versus bottom-up' dichotomy. Its mathematical explicitness and consideration of micro-behavior eliminate mechanistic black boxes, and lead to more realistic, testable predictions. All models, however, require simplifications that do not always satisfy the natural historian. Ours is no different, and we offer the following caveats.

First, we considered only 2 resources, $115 \mathrm{~g}$ herring and $525 \mathrm{~g}$ pollock, whereas seals use additional resources (Iverson et al. 1997). Also, parameterization did not consider seasonal variation in resources within the February to June period considered. Nonetheless, herring and pollock appear to dominate the diet of seals (Iverson et al. 1997) and comprise the dominant biomass in PWS during late winter and early spring (R. E. Thorne unpublished data). While we acknowledge that future studies should consider finer scale seasonality and a wider range of fish species and size classes, our parameterization is adequate for initial hypothesis development. Another simplifying assumption was that patches do not deplete, and thus energy intake rate is a linear function of patch residence time, which might be unrealistic. A decelerating intake rate function might amplify the indirect effect of resource decrements on predation rate and should be considered by future studies.

Second, although there were no differences in seal behavior and foraging success between the scenarios with and without risk from sharks, simulations were not designed explicitly to compare the influence of a surface versus an at-depth predator. Killer whale risk at the surface during the night (when foraging occurred) was 6 times greater than shark risk at the foraging patch (Table 2). At the time of model development there was no information with which to evaluate the realism of that scenario. Since then, our ongoing empirical analyses suggest that we greatly underestimated the relative abundance of sharks in the current parameterization, and that sharks may actually influence the risk-energy trade-off experienced by seals more strongly than do killer whales (A. Frid unpublished data). Our ongoing modeling and empirical analyses address this issue.

Third, in our simulations seals used only the $100 \mathrm{~m}$ deep patch, and did not forage in shallower strata, which contradicts empirical data showing that harbor seals in PWS and elsewhere in Alaska forage through- out the water column (Hastings et al. 2004). This inconsistency probably arose from the underestimated shark risk discussed above, which would increase the security of deep strata relative to shallow ones. Also, resource encounter probabilities were based on median values for depth-specific fish biomass (Appendix 2). Consequently, parameterization did not adequately capture large ephemeral aggregations of herring near the surface, exaggerating the low expected energy gain of foraging in shallow strata. Thus, the conditions discouraging shallow foraging in the model may not represent those experienced by seals in recent studies (see Hastings et al. 2004). Future simulation studies should experimentally vary the relative abundance of predators and resources in deep versus shallow strata.

A final caveat is that although haulouts are refuges from sharks and killer whales, Alaska native subsistence hunting activities focus on these locations. While risk from hunters is beyond the scope of this model, it could well be that hunters not only inflict direct mortality, but also indirectly increase predation rates from sharks and killer whales by discounting the expected benefit and reducing the actual use of haulouts for safety from these predators (see Dill et al. 2003). It would be interesting for future simulation studies to vary the levels of human hunting and of resources factorially and predict shark and killer whale predation rates for these scenarios.

The above caveats qualify our inferences on seal behavior without diminishing our general conclusion. Our model suggests, as a theoretically plausible hypothesis, that overfishing and other factors that reduce fish populations indirectly increase predation rates on pinnipeds. This hypothesis could be quite relevant to analyses of the harbor seal decline in PWS. Pacific herring collapsed (Thomas \& Thorne 2003) and other resources shifted availability (Anderson \& Piatt 1999) concurrent with the decline, yet evidence for nutritional limitation is lacking (Fadely 1997, Trumble \& Castellini 2002b, Trumble et al. 2003, K. J. Frost unpubl. data, A. Hoover-Miller unpubl. data). Similar mechanisms may be inherent to other pinniped declines (e.g. Bowen et al et al. 2003). By explicitly considering behavior and addressing indirect interactions between species, our model contributes towards a more diverse toolbox for resource managers attempting to optimize fisheries exploitation and focal species conservation (Alonzo et al. 2003, Okey \& Wright 2004).

Acknowledgements. Funding was provided by grants to A.F. and colleagues from the North Pacific Research Board, the Alaska Department of Fish \& Game, and the PADI Project AWARE Foundation. L.M.D.'s research is supported by NSERC Canada grant A6869. S. H. Alonzo and B. Roitberg 
reviewed earlier drafts. C. W. Clark and R. Ydenberg influenced early development of the work. Model parameterization was possible thanks to R. E. Thorne, G. Blundell, L. Hulbert, J. Burns, K. J. Frost, C. Matkin, and R. W. Baird. For other essential feedback or information, we thank the Behavioural Ecology Research Group at Simon Fraser University (especially the Dill Laboratoy), the Marine Mammal Research Unit at the University of British Columbia (especially V. Deecke and D. Tollit), R. J. Small, P. Cottrell, S. Moffitt, S. Trumble, M. Sigler, A. Hoover-Miller, and constructive anonymous reviewers

\section{LITERATURE CITED}

Alonzo SH, Switzer PV, Mangel M (2003) An ecosystembased approach to management: using individual behavior to predict the indirect effects of Antarctic krill fisheries on penguin foraging. J Appl Ecol 40:692-702

Anderson PJ, Piatt JF (1999) Community reorganization in the Gulf of Alaska following ocean climate regime shift. Mar Ecol Prog Ser 189:117-123

Anholt, BR, Werner, EE (1995) Interactions between food availability and predation mortality mediated by adaptive behavior. Ecology 76:2230-2234

Anthony JA, Roby DD, Turco KR (2000) Lipid content and energy density of forage fishes from the northern Gulf of Alaska. J Exp Mar Biol Ecol 248:53-78

Baird RW (1994) Foraging behavior and ecology of transient killer whales. PhD thesis. Simon Fraser University, Burnaby

Beck CA, Bowen WD, Iverson SJ (2000) Seasonal changes in buoyancy and diving behavior of adult grey seals. J Exp Biol 203:2323-2330

Biro PA, Post JR, Parkinson EA (2003) From individuals to populations: prey fish risk-taking mediates mortality in whole-system experiments. Ecology 84:2419-2431

Bowen WD, Iverson SJ, Boness DJ, Oftedal OT (2001) Foraging effort, food intake, and lactation performance depend on maternal mass in a small phocid seal. Funct Ecol 15: 325-332

Bowen WD, Ellis SL, Iverson SJ, Boness DJ (2003) Maternal and newborn life-history traits during periods of contrasting population trends: implications for explaining the decline of harbour seals (Phoca vitulina), on Sable Island. J Zool 261:55-163

Boyd IL (1997) The behavioral and physiological ecology of diving. Trends Ecol Evol 12:213-217

Boyd IL (2000) State-dependent fertility in pinnipeds: contrasting capital and income breeders. Funct Ecol 14:623-630

Clark CW, Mangel M (2000) Dynamic state variable models in ecology. Oxford University Press, New York

Davis RW, Williams TM, Kooyman GL (1985) Swimming metabolism of yearling and adult harbor seals Phoca vitulina. Physiol Zool 58:590-596

Dill LM, Heithaus MR, Walters C (2003) Behaviorally-mediated indirect interactions in marine communities and their conservation implications. Ecology 84:1151-1157

Fadely BS (1997) Investigations of harbor seal Phoca vitulina health status and body condition in the Gulf of Alaska. $\mathrm{PhD}$ thesis, University of Alaska at Fairbanks, AK

Frost KJ, Lowry LF, Ver Hoef JM (1999) Monitoring the trend of harbor seals in Prince William Sound, Alaska, after the Exxon Valdez Oil Spill. Mar Mamm Sci 15:494-506

Frost KJ, Simpkins MA, Lowry LF (2001) Diving behavior of subadult and adult harbor seals in Prince William Sound, Alaska. Mar Mamm Sci 17:813-834
Hastings KK, Frost KJ, Simpkins MA, Pendleton GW, Swain UG, Small RJ (2004) Regional differences in diving behavoir of harbor seals in the Gulf of Alaska. Can J Zool 82:1755-1773

Heithaus MR, Frid A (2003) Optimal diving under the risk of predation . J Theor Biol 223:79-92

Houston AI, McNamara JM, Heron JE, Barta Z (2003) The effect of foraging parameters on the probability that a dive is successful. Proc R Soc Lond B Biol Sci 2451-2455

Iverson SJ, Frost KJ, Lowry LF (1997) Fatty acid signatures reveal fine scale structure of foraging distribution of harbor seals and their prey in Prince William Sound, Alaska. Mar Ecol Prog Ser 151:255-271

Kramer DL (1988) The behavioral ecology of air breathing by aquatic animals. Can J Zool 66:89-94

Krebs CJ, Boutin S, Boonstra R, Sinclair ARE, Smith JNM, Dale MRT, Martin K, Turkington R (1995) Impact of food and predation on the snowshoe hare cycle. Science 269: 1112-1115

Lima SL, Dill LM (1990) Behavioral decisions made under the risk of predation. Can J Zool 68:619-640

Lowry LF, Frost KJ, Ver Hoef JM, DeLong RA (2001) Movements of satellite-tagged subadult and adult harbor seals in Prince William Sound, Alaska. Mar Mamm Sci 17:835-861

Lucas Z, Stobo WT (2000) Shark-inflicted mortality on a population of harbour seals (Phoca vitulina) at Sable Island, Nova Scotia. J Zool 252:405-414

Luttbeg B, Rowe L, Mangel M (2003) Prey state and experimental design affect relative size of trait- and densitymediated indirect effects. Ecology 84:1140-1150

McNamara JM, Houston AI (1987) Starvation and predation as factors limiting population size. Ecology 68:1515-1519

Mori Y (1998) The optimal patch use in divers: optimal time budget and the number of dive cycles during bout. J Theor Biol 190:187-199

Mori Y, Boyd IL (2004) The behavioral basis for nonlinear functional responses and optimal foraging in Antarctic fur seals. Ecology 85:398-410

National Research Council (2003) Decline of the Steller sea lion in Alaskan waters. National Academy Press, Washington, DC

Okey TA, Wright B (2004) Toward ecosystem-based extraction policies for Prince William Sound, Alaska: integrating conflicting objectives and rebuilding pinnipeds. Bull Mar Sci 74:727-747

Pauly D, Christensen V, Guénette S, Pitcher TJ, Sumaila UR, Walters CJ, Watson R, Zeller D (2002) Towards sustainability in world fisheries. Nature 418:689-695

Saulitis E, Matkin C, Heise K, Barrett-Lennard L, Ellis GM (2000) Foraging strategies of sympatric killer whale (Orcinus orca) populations in Prince William Sound, Alaska. Mar Mamm Sci 16:94-109

Scheel D, Matkin C, Saulitis E (2001) Distribution of killer whale pods in Prince William Sound, Alaska over a thirteen-year period, 1984-1996. Mar Mamm Sci 17:555-569

Sigler MF, Hulbert LB, Lunsford CR, Thompson NH, Burek K, Hirons A, O'Corry-Crowe GM (in press) Diet of Pacific sleeper shark, a potential Steller sea lion predator, in the Northeast Pacific Ocean. J Fish Biol

Simpkins MA, Kelly BP, Wartzok D (2001) Three-dimensional analysis of search behavior by ringed seals. Anim Behav 62:67-72

Sinclair ARE, Arcese P (1995) Population consequences of predation-sensitive foraging: the Serengeti wildebeest. Ecology 76:882-891

Springer AM, Estes JA, van Vliet GB, Williams TM, Doak DF, Danner EM, Forney KA, Pfister B (2003) Sequential 
megafaunal collapse in the North Pacific Ocean: an ongoing legacy of industrial whaling? Proc Natl Acad Sci USA 100:12223-12228

Thomas GL, Thorne RE (2003) Acoustical-optical assessment of Pacific herring and their predator assemblage in Prince William Sound, Alaska. Aquat Living Resour 6:247-253

Thompson D, Fedak MA (2001) How long should a dive last? A simple model of foraging decisions by breath-hold divers in a patchy environment. Anim Behav 61:287-296

Trumble SJ, Castellini MA (2002a) Digestive efficiency of pollock and herring in harbor seals: addressing the 'is it food?' hypothesis. FASEB J 16:A47-A47

Trumble SJ, Castellini MA (2002b) Blood chemistry, hematology, and morphology of wild harbor seal pups in Alaska. J Wildl Manag 66:1197-1207

Trumble SJ, Barboza PS, Castellini MA (2003) Digestive constraints on an aquatic carnivore: effects of feeding fre-

Editorial responsibility: Otto Kinne (Editor-in-Chief), Oldendorf/Luhe, Germany quency and prey consumption on harbor seals. J Comp Physiol B 173:501-509

Ver Hoef JM, Frost KJ (2003) A Bayesian hierarchical model for monitoring harbor seal changes in Prince William Sound, Alaska. Environ Ecol Stat 10:201-209

Werner EE, Peacor SD (2003) A review of trait-mediated indirect interactions in ecological communities. Ecology 84: 1083-1100

Williams TM, Davies RW, Fuiman LA, Francis J, Le Boeuf BJ, Horning M, Calambokidis J, Croll DA (2000) Sink or swim: strategies for cost-efficient diving by marine mammals. Science 288:133-136

Wilson RP (2003) Penguins predict their performance. Mar Ecol Prog Ser 249:305-310

Ydenberg RC, Clark CW (1989) Aerobiosis and anaerobiosis during diving by Western Grebes: an optimal foraging approach. J Theor Biol 139:437-439

Submitted: March 30, 2005; Accepted: September 27, 2005 Proofs received from author(s): March 13, 2006 